\title{
Design and dimensioning of a complex timber-glass hybrid structure: the IFAM pedestrian bridge
}

\author{
Till Vallee • Cordula Grunwald • \\ Lena Milchert • Simon Fecht
}

Received: 23 December 2015 / Accepted: 23 February 2016 / Published online: 8 March 2016

(C) Springer International Publishing Switzerland 2016

\begin{abstract}
Research has repeatedly pointed out the suitability of adhesive bonding to substitute to "traditional" joining techniques for numerous materials and loads, including timber to glass. Practitioners, however, are still reluctant to implement them into their designs. Adhesion as a method of joining, particularly in the context of hybrid structures, presupposes knowledge of all involved materials, including codes and procedures; most practitioners however tend to be focused on just a subset of materials. While such specialization is not unusual, it makes it challenging to implement novelty (i.e. new materials or techniques). Additionally, when it comes to adhesion where most of the knowledge has been generated by chemists, the lines become even more blurred. Taking the example of a pedestrian timber-glass bridge, this research shows how design and dimensioning of complex bonded hybrid structures can be performed in accordance with "traditional" engineering practice. The paper guides through every step, from the first concepts to the final design, including the manufacturing, of a relatively complex structure, in which timber and glass act together as equivalent members. The compliance of this process with engineering models is emphasized, and the embedment into existing codes and standards is sought after to ensure acceptancy by practitioners.
\end{abstract}

T. Vallee $(\varangle) \cdot$ C. Grunwald · L. Milchert · S. Fecht Fraunhofer Institute for Manufacturing Technology and Advanced Materials IFAM, Wiener Strasse 12, 28359 Bremen, Germany e-mail: till.vallee@ifam.fraunhofer.de
Keywords Glass · Timber · Bonding · Hybrid · Design

\section{Introduction}

\subsection{Structural gazing and silicones}

The use of glass in architecture has steadily increased over the last decades, with a well-established own discipline: structural glazing. The authors judged that this is not the right forum the list the milestones of structural glazing, for which much more detailed publications are available. Structural engineering had to follow by offering specific technical solutions for joining very dissimilar materials, as steel, concrete, timber to glass. By its inherent very brittle nature, connecting glass is a challenging task, in particular if glass is to be part of the structural system.

The natural reflex engineers developed towards the issue of brittleness was for long time, and still is, to limit as much as possible the global structure from the critical glass elements; this is either achieved through mechanical connectors, or by the use of very flexible adhesives that greatly reduce stresses in general, and stress peaks in particular. This design philosophy is perfectly mirrored in the reference code for structural glazing at the European level, the ETAG 002, which implicitly enforces the limitation to silicones as adhesives. Silicones, by their relatively low stiffness, if compared to other adhesive classes commonly used 


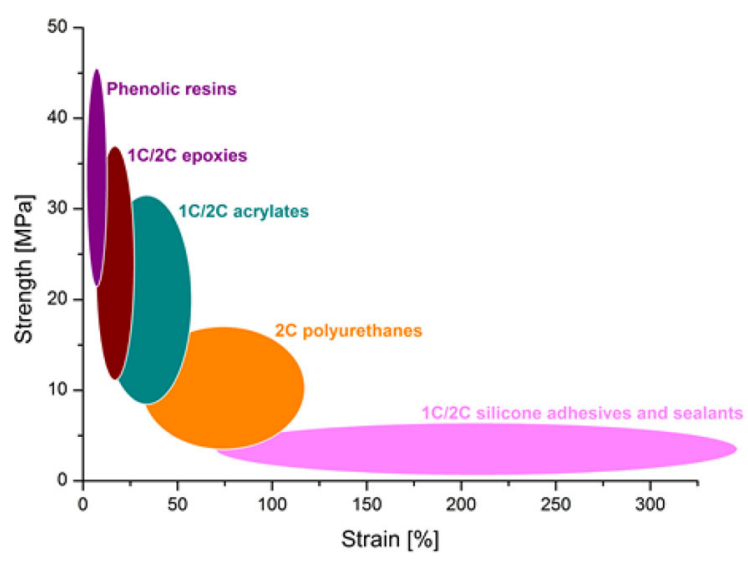

Fig. 1 Strength and strain performance of different adhesive classes

for structural purposes (cf. Fig. 1), allow for large relative deformations, but at the price of relatively low strength; effects like silicone's significant tendency to creep, respectively the associated low creep resistance, pose additional limits on the mechanical performance of silicone joints, respectively hybrid structures joined thereof and in which glass is expected to be structurally active.

\subsection{Hybrid timber-glass structures}

Owing to their architectural and aesthetical qualities, timber-glass hybrid structures have, in recent years, increasingly been in the focus of research, and on a limited basis of industrial application. Among the first to report on adhesively bonded timber-glass connections were Cruz and Pequeno (2008) who performed shear tests on Douglas fir bonded to laminated and tempered glass using silicones, polyurethanes, acrylates and epoxies. The results showed a strong dependency of the fracture behaviour on the adhesive stiffness, with two extreme situations occurring: adhesives exhibiting high strength and stiffness but brittle failure, and ductile and flexible adhesives with low mechanical resistance. The authors advocated the use of the "best balance" between these two. In subsequent research Pequeno and Cruz (2009) experimentally investigated hybrid timber-glass beams and panels with spans of up to $3200 \mathrm{~mm}$ in 4-point-bending. In comparison to equivalent traditional timber panels, capacity and stiffness were significantly higher, leading the authors to conclude that "timber provides ductility and glass offers stiffness". In a further study, the experimental findings were successfully numerically modelled (Cruz et al. 2010). Modular panels of timber and glass started being developed from 2006 on in Austria and Germany, by using timber and glass combined with different adhesives (silicones, polyurethanes and acrylate), e.g. Edl (2008). These investigations were followed by Neubauer (2011) from short term static loads toward cyclic loads and long term loads (up to 90 days) at room temperature and at $55^{\circ} \mathrm{C}$. Among the results it could be shown that acrylates exhibited higher stiffness and ultimate strength; however they were more prone to strength and stiffness reductions under elevated temperatures and $\mathrm{MC}$, as well as being strongly creep-sensitive.

Hochhauser (2011) investigated timber frames stabilized with glass panels and reported increased capacities by using silicones as line element and epoxy on the edges of the glass. Müller (2011), used acrylate manufactured timber-glass I-beams with spans up to $8 \mathrm{~m}$; in bending tests failure occurred by crushing the timber in compression, however the necessity of further investigating the long term behaviour of the adhesive was acknowledged. Rinnhofer (2014) experimented with on timber-glass specimens using silicone, and determined that long-term loading (12 months) reduced significantly reduced the capacity when compared to short term results. Kreher et al. (2004) report on an industrial implementation of timber-glass composite girders consisting of glass webs and wood flanges bonded by a hot-melt polyurethane. Based on laboratory tests, creep under "assumed maximum loads" was expected stabilize after 4 weeks; measurements on-site showed deformations amounting for only a third of the expected value, this differences likely to be attributed to a much lower MC. Similar research was carried out by Kozłowski (2012) and Blyberg et al. (2012, 2014) on timber-glass I-beams, timber-glass columns and timber-glass frames, all bonded using several types of adhesives. Among the counterintuitive findings of these studies was the fact that adhesively bonding glass is not always to be performed using extremely soft silicones or acrylates, but that structural epoxies might represent an more appropriate substitute; this result is insofar interesting, because structural epoxies exhibit a much better behaviour under environmental loads, and are thus more durable.

To the knowledge of the authors, the only economically successful implementation of Timber-Glass 
composite systems is the UNIGLAS $®$ facade developed jointly by the company from which its name is derived and Holzforschung Austria, most prominently by Hochhauser and Winter (2013), Fadai and Winter (2014), and Jiang et al. (2014): It consists of glass panels bonded onto "patented serrated wooden connecting strips" by means of a $2 \mathrm{C}$ silicone adhesive; it is subsequently mechanically fixed onto the timber structure. The choice of the silicone is based on the fact that it allows for dimensioning according to ETAG 002. However, silicone are prone to creep, thus the characteristic long-term strength is dramatically reduced (up to $10 \%$ of short term strength).

\subsection{Scope of this research}

When designing hybrid structures in which glass is expected to act structurally, with connections supposed to be ensured by means of adhesion, the designer is faced with two contradictory options regarding the choice of the adhesive: firstly, choosing an adhesive with relatively low stiffness to avoid as much as possible the emergence of stress peaks, with the drawback of limited mechanical strength mostly further limited by a tendency to creep; secondly, favouring strength and reduced creep by selecting adhesives with higher mechanical strength properties, usually stiffer, and consequently prone to stress concentrations. Designing structures in which adhesives are the only joining method makes it necessary to adapt the design to the adhesive, which is far more effective than adapting the adhesive to the design. When bonded structures are designed such that "traditional" joining methods, e.g. mechanical fasteners, are "just replaced" by adhesives, according to Peters (1996) the design process is still in the so called substitution phase, and the resulting product is usually underperforming (cf. Mainstone 1997). A prominent example of such structures designed in midst of their substitution phase is the Pontresina G-FRP bridge (Keller 1999), a truss structure in which joints initially thought as bolted were adhesively bonded.

The aim of the research presented hereafter is to show a methodology on how to design a complex timber-glass hybrid structure off the beaten tracks by following some basic principles, but also to hint at methods to structurally design such a structures as close as possible to existing codes.

\section{Design principles}

\subsection{Some design principles}

Among the principles of good design with bonded structures the most basic is certainly to increase as much as possible the bonded surfaces, in particular when materials with very dissimilar properties are considered. The latter is particularly true when one substrate (as glass) lacks ductility, which prohibits load redistributions within parts made thereof. Another basic design principle associated with adhesives is to favour shear stresses, to limit axial (tensile) stresses, and to avoid situations in which adhesives are subjected to peel loads. In addition to the two aforementioned principles, the authors considered that the manufacturing process, and difficulties associated with it, should be considered in a very early design state so to ensure that the resulting bonded connections are as flawless as possible by allowing for simple access of the surfaces to bond. A second class of principles followed for the design was to not restrict the choice of materials by "common sense", e.g. limiting potential adhesives to silicones with the sole reason that codes quasi enforce them; a similar broadening of materials was followed when selecting the timber, for which not only spruce, the "traditional" material in timber engineering, but to extend it towards hardwoods (herein beech and oak).

\subsection{The design process}

Following the design principles discussed above, namely increasing the bonded surfaces in which adhesive is stressed under shear, allowing for a direct access to the bonded areas, and extending the range of adhesives and timber species, a pedestrian bridge approx. $1 \mathrm{~m} 50$ in width and spanning approx. 10m was planned. Only timber beams and glass panels were considered as materials.

Truss structures were rules out right from the beginning, because of the very nature of their typology; they would concentrate their loads in traction and compression in the struts, with relatively small bonded areas, as emphasised by Fig. 2. Curved structures, e.g. arched although possible in GLT, were ruled out for the costs associated with manufacturing cost of corresponding glass panels. The structural typology followed for the design was the Vierendeel beam (sketched in Fig. 2), a structure where the members are not triangulated 
Fig. 2 Structural principles of the complex timber-glass hybrid structure (early design variants): (top) truss, (bottom) Vierendeel
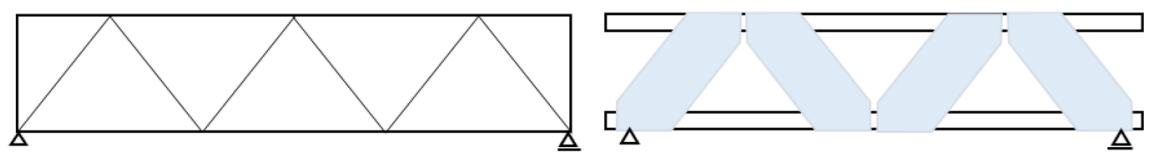
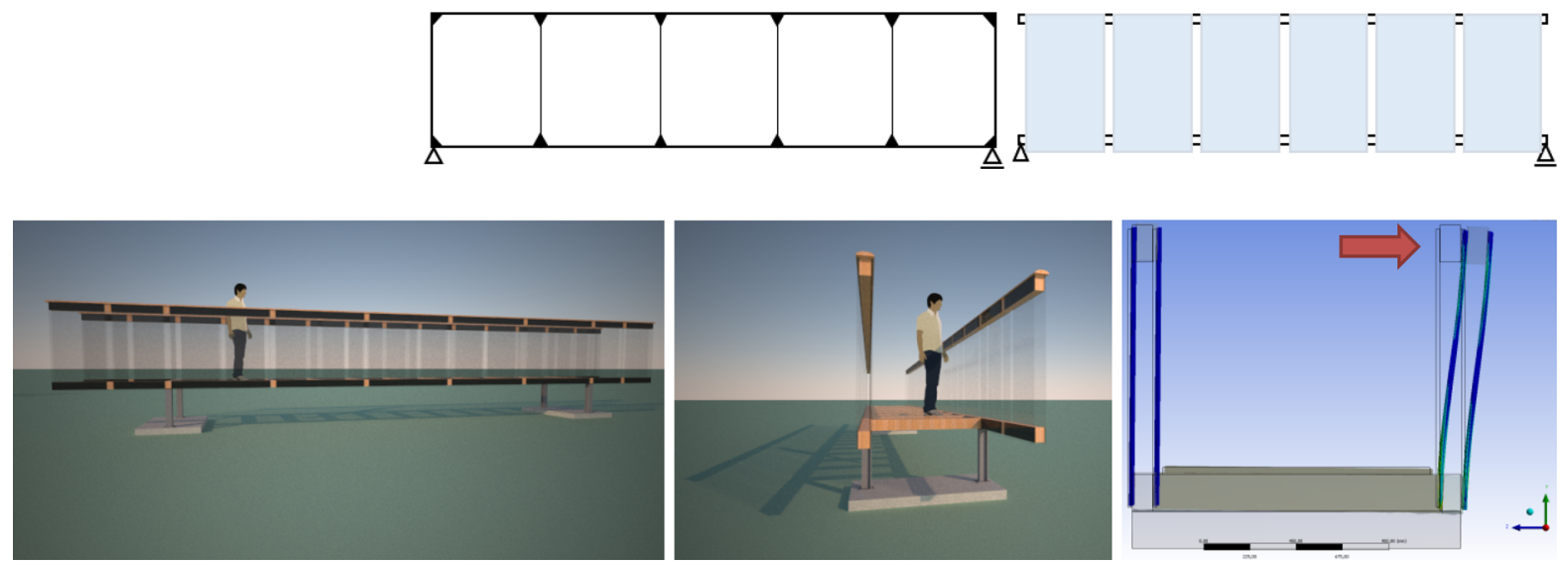

Fig. 3 Structural principle of the complex timber-glass hybrid structure (intermediary design variant): (left) elevation, (center) crosssection, (right) lateral stability by bonding pairs of glasses (the red arrow indicates a lateral force)

(as in trusses) but form rectangular openings, and is a frame with fixed joints that are capable of transferring and resisting bending moments. The following sections describes the structural logic, structural calculations based thereupon will be presented separately.

The Vierendeel typology was structurally implemented by considering upper and lower chords composed of two pairs of rectangular timber beams. On each side of the bridge, one upper and one lower timber beam are to be connected by pairs of glass panels via corresponding adhesive layers. This structural logic leads in fine to two sets of Vierendeel beams that are to be connected by means of transversal beams. The transversal beams serve as a support for glass panels that act as running surface. An intermediary design variant following the outlined principles is depicted in Fig. 3.

For obvious structural reasons, the upper and lower chords, herein the timber beams, need to be structurally continuous; considering the total length of the bridge, $\mathrm{L} \approx 10 \mathrm{~m}$, glued laminated timber (GLT) beams were considered. The glass panels however, following the logic of the Vierendeel-beam, do not need to be continuous (in which case the whole system would degenerate to an I-beam); therefore glass-panels of equal sizes were distributed along the length of the bridge. Dividing the glass surface into panels presents several advantages; among the most important is the increase in redundancy, since it allows for a pre-defined number of panels to fail without jeopardizing the integrity of the whole structure.

Besides lower costs, because much cheaper standardized panels could be used, additional advantages results from the much simpler handling smaller panels allow for, if compared with panels over the complete length. The upper and lower chords of each Vierendeelbeam were connected via pairs of panels, instead of just one, in order to ensure lateral stiffness; the lateral stiffness results from the rigid connection between the timber and the glass which is achieved via the large bonded surface. The structural logic behind the lateral stiffening is best represented by Fig. 3 .

Global lateral stiffness is achieved by rigidly connecting both individual Vierendeel-beams; thus, in the design, the lateral beams must be connected accordingly; glued-in rods, in combination with rounded dove-tail connections, are being considered as a mean to achieve a connection able to transmit bending moments.

\subsection{Manufacturing process}

The manufacturing process for the timber-glass hybrid structure must simplify as much as possible the bond- 


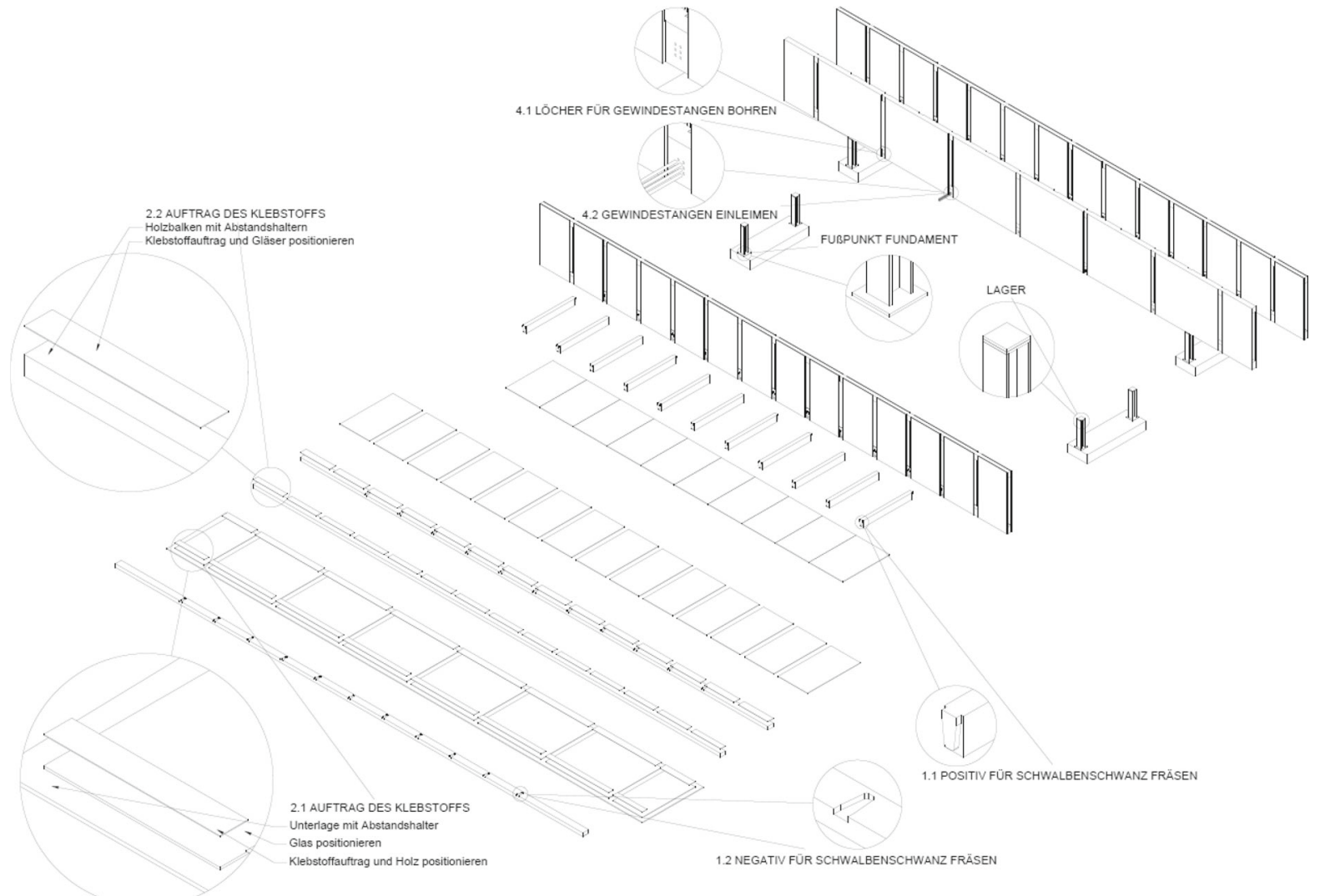

Fig. 4 Principle of assembling the hybrid timber-glass structure

ing process, which is considered as the most critical. It is intended to manufacture the bridge in the sequence sketched herein, which is depicted in Fig. 4: Firstly, prepare the transverse beams by milling the rounded dove-tails and drilling the holes for the glued-in rods; Secondly, lay down the upper and lower chords, pour the adhesive in the desired thickness, place the glass panels, and leave to cure; Thirdly, once cured, reverse the upper and lower chords, pour the adhesive on the other side, place the glass panels, and leave to cure; Fourthly, place both Vierendeel panels upright, position the transverse beams, and fix them together by means of glued-in rods; Fifthly, uplifting of the bridge on top of its bearing, then placing the glass panels to form the running surface. The timing of the assembly is mostly dictated by the curing time of the adhesives used.

\section{Materials}

\subsection{Adhesives}

As already stated in the introduction, the most critical material for the considered hybrid structure is the adhesive. Its selection is based upon considerations on strength and stiffness; additional fundamental constraints on the adhesive result from its ability to achieve sufficient adhesion on substrates, glass and timber. In the frame of this investigation, 5 different adhesives reported in literature to have been considered for timber-glass structures were investigated: adhesive classes as diverse as (1C and $2 \mathrm{C}$ ) polyurethanes, acrylates, (2C) epoxies and (2C) epoxysilanes were included, covering a range of lap shear strength from 4.5 MPa (SikaFlex265) to $28 \mathrm{MPa}$ (SikaPower 477R), a 
Table 1 Technical data of the considered adhesives

\begin{tabular}{|c|c|c|c|c|c|}
\hline $\begin{array}{l}\text { Adhesive designation in } \\
\text { this study }\end{array}$ & 1KPU polyurethane & STEP epoxysilane & AKR acrylate & EP epoxy & 2KPU polyurethane \\
\hline Commercial name & Sikaflex 265 & Collano RS 8509 & Sikafast $5221 \mathrm{NT}$ & Sikapower 477 R & Sikaforce 7818 L7 \\
\hline $\begin{array}{l}\text { Stiffness at RT (MPa) } \\
\text { acc. data sheet }\end{array}$ & Not given & 60 & 250 & 1700 & 2500 \\
\hline Glass transition $\mathrm{T}_{G}\left({ }^{\circ} \mathrm{C}\right)$ & -54.3 & $<-50$ & 57.1 & 61.5 & 51.1 \\
\hline $\begin{array}{l}\mathrm{E}^{\prime} \text {-modulus at } \\
\quad-20^{\circ} \mathrm{C}\left(\mathrm{N} / \mathrm{mm}^{2}\right)\end{array}$ & 18 & 43 & 1052.0 & 1792.0 & 2057.0 \\
\hline $\begin{array}{l}\mathrm{E}^{\prime} \text {-modulus at } \\
25^{\circ} \mathrm{C}\left(\mathrm{N} / \mathrm{mm}^{2}\right)\end{array}$ & 6.4 & 22 & 267.4 & 1569.9 & 1919.0 \\
\hline $\begin{array}{l}\mathrm{E}^{\prime} \text {-modulus at } \\
80^{\circ} \mathrm{C}\left(\mathrm{N} / \mathrm{mm}^{2}\right)\end{array}$ & - & 7 & 1.9 & 22.9 & 18.46 \\
\hline $\begin{array}{l}\text { Lap shear strength } \\
(\mathrm{MPa}) \text { acc. data sheet }\end{array}$ & 4.5 & 7.0 & 10.0 & 28.0 & 20.0 \\
\hline $\begin{array}{l}\text { Strain at rupture }(\%) \\
\text { acc. data sheet }\end{array}$ & 450 & 250 & 200 & 3 & 2.5 \\
\hline
\end{tabular}

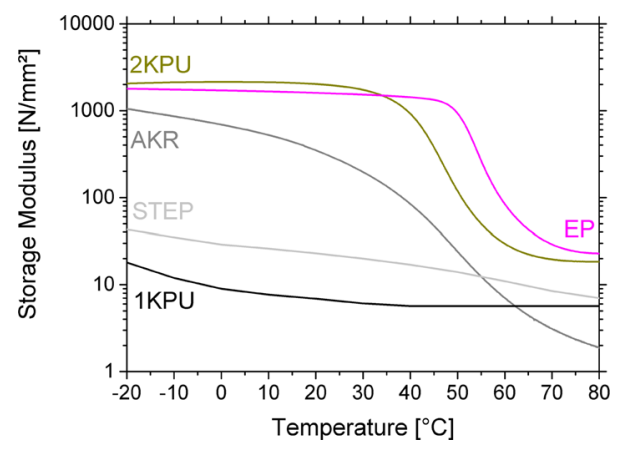

Fig. 5 Results of the DMA on all adhesives considered

range of stiffness varying from 10 to $2500 \mathrm{MPa}$. Table 1 summarizes the main properties of the adhesives considered; this data is complemented by a DMA of all adhesives, with the results being reported in Fig. 5.

\subsection{Timber}

Timber can broadly be divided into softwood and hardwood, the former coming from conifers such as Spruce and Pine, while the latter from angiosperm trees such as Beech and Oak. Both categories exhibit significant differences in their properties, which can be tracked down to fundamentally different anatomies. Softwood is currently to a very large proportion processed for structural building applications. Hardwoods exhibit a more complex anatomy that includes the presence of pores, or vessels. Although beech and oak are currently only rarely used as a construction material its abundant availability in Central Europe and its high mechanical resistance make it a promising material for structural applications. In the framework of the design of the pedestrian bridge, three timber species were considered: firstly, the most frequently used softwood in timber engineering, spruce; secondly and thirdly, two representatives of hardwoods were selected for their expected mechanical resistance (beech) and enhanced durability (oak), if compared to spruce, beech and oak.

Considering the dimensions envisioned for the design, all three timber species would be used in the form glued laminated timber beams (GLTB); GLTB is delivered in different qualities, herein the highest quality, corresponding to GL32h according to DIN 1052. Characteristic values are tensile strength of 22.5 $\mathrm{MPa}$, shear strength of $3.5 \mathrm{MPa}$ and a stiffness of $\mathrm{E}=$ $13,700 \mathrm{MPa}$. It must be emphasised that these characteristic values severely underestimate the real mechanical performance in tension and compression perpendicular to fibres, even considering characteristic values (5\%-quantile, cf. Fecht et al. 2013), in particular regarding hardwoods: $\mathrm{f}_{t, 0, k}=38.6 \mathrm{MPa}, \mathrm{f}_{t, 90, k}=10.6$ $\mathrm{MPa}$, and $\mathrm{f}_{v, k}=13.4 \mathrm{MPa}$.

Timber engineering codes (herein EC5) additionally require the characteristic value of strength to be reduced depending upon the intended usage, which is defined in terms of service class, respectively load duration classes. Herein, service class 3 is envisioned, which 

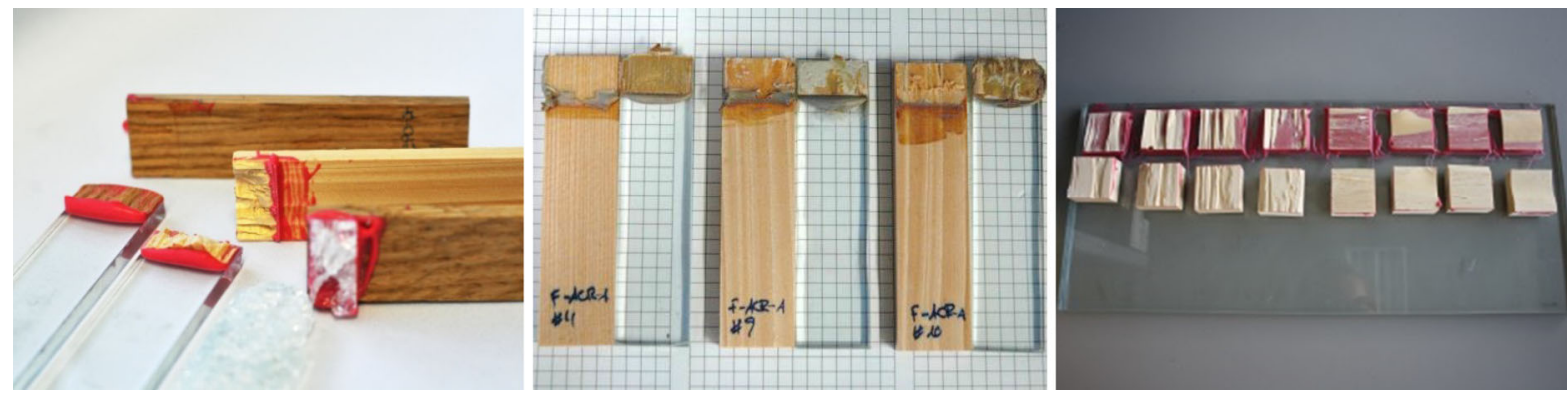

Fig. 6 Lap shear tests, selected specimens after testing: (left) SikaDur477R before weathering on (back) beech, (middle) spruce, (front) oak; (centre) after weathering cohesive failure of

acrylate on spruce; (right) compressive shear tests after failure (spruce and epoxy)

Table 2 Lap shear strengths, failure modes (nomenclature following ASTM D5573, failure modes are representative for all tests; $A D H$ Adhesive failure, $F T$ fibre-tear failure, $L F T$ light-fibre-tear failure, $S B$ stock-break failure)

\begin{tabular}{llllll}
\hline Adhesive & 1KPU & STEP & AKR & EP & 2KPU \\
\hline Spruce & $3.35 \pm 0.48 \mathrm{MPa}$ & (Not tested) & $3.62 \pm 1.27 \mathrm{MPa}$ & $12.94 \pm 0.48 \mathrm{MPa}$ & $1.74 \pm 1.27 \mathrm{MPa}$ \\
& ADH at timber & & ADH and LFT & FT and SB & ADH and few LFT \\
Beech & $3.17 \pm 0.53 \mathrm{MPa}$ & $4.88 \pm 0.49 \mathrm{MPa}$ & $6.11 \pm 0.27 \mathrm{MPa}$ & $16.89 \pm 2.89 \mathrm{MPa}$ & $0.79 \pm 0.89 \mathrm{MPa}$ \\
& ADH at timber & LFT and ADH & ADH and LFT & FT and SB & ADH \\
Oak & $3.42 \pm 0.33 \mathrm{MPa}$ & $9.20 \pm 0.92 \mathrm{MPa}$ & $5.31 \pm 0.33 \mathrm{MPa}$ & $18.12 \pm 1.17 \mathrm{MPa}$ & $3.96 \pm 1.92 \mathrm{MPa}$ \\
& ADH at timber & LFT and ADH & ADH and LFT & FT and SB & ADH \\
\hline
\end{tabular}

leads to reduction factors of 0.385 for constant loads (dead load), and 0.538 for short term loading (live load and uniform line load on handrail).

\subsection{Glass}

The glass panels envisioned for the bridge should consist of tempered safety glass. For the vertical panels, laminated safety glass consisting of two individual laminated plates are considered, while for the running surface it should consist of three layers. As it will be shown later in the calculations, stresses generated inside the glass panels are relatively small, so that glass is not the limiting factor in the design. As a consequence, no further emphasis on the glass panels, their quality and mechanical properties will be detailed.

\section{Experimental investigations on the timber-glass bonded connections}

\subsection{Shear-tensile tests}

In order to verify the ability of the adhesives to adhere on the timber, respectively on the glass, lap shear tests according to DIN EN 1465 were performed on all combinations of adhesives (thickness $1 \mathrm{~mm}$ ) and timber and glass. Selected test results are displayed in Fig. 6 and Table 2 summarizes the results, which represent the average of three replications. It appears that in all cases the 2C epoxy (Sikapower $477 \mathrm{R}$ ) leads to the highest lap shear strengths, if compared to the other adhesives, and that the lap shear strength is significantly higher for the hardwoods, if compared to the softwood (spruce). For oak, the performance is highest for the epoxy, second for the silane-based epoxy, followed by the acrylate and the $1 \mathrm{C}$ polyurethane.

\subsection{Shear-tensile tests after weathering}

To investigate the effect of climatic variations on the lap shear strength, in particular stresses and strains induced by the swelling of the different timber species, additional lap shear specimens were subjected to simultaneous cyclic variations of temperature and humidity. In each cycle, temperature was maintained for $12 \mathrm{~h}$ at $-20{ }^{\circ} \mathrm{C}$ at a relative humidity level of $60 \%$, then raised to $+80{ }^{\circ} \mathrm{C}$ and $95 \%$ rel. humidity for another $12 \mathrm{~h}$; the combination of both periods of $12 \mathrm{~h}$ being 

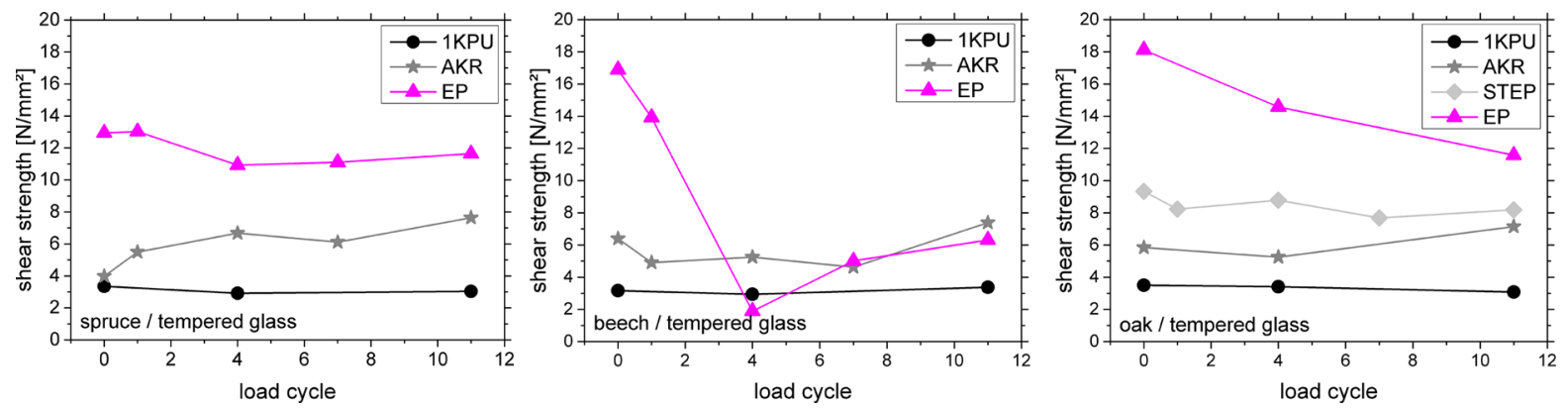

Fig. 7 Lap shear strength for all combinations of adhesives, and glass before and after aging, (left) spruce, (centre) beech, (right) oak
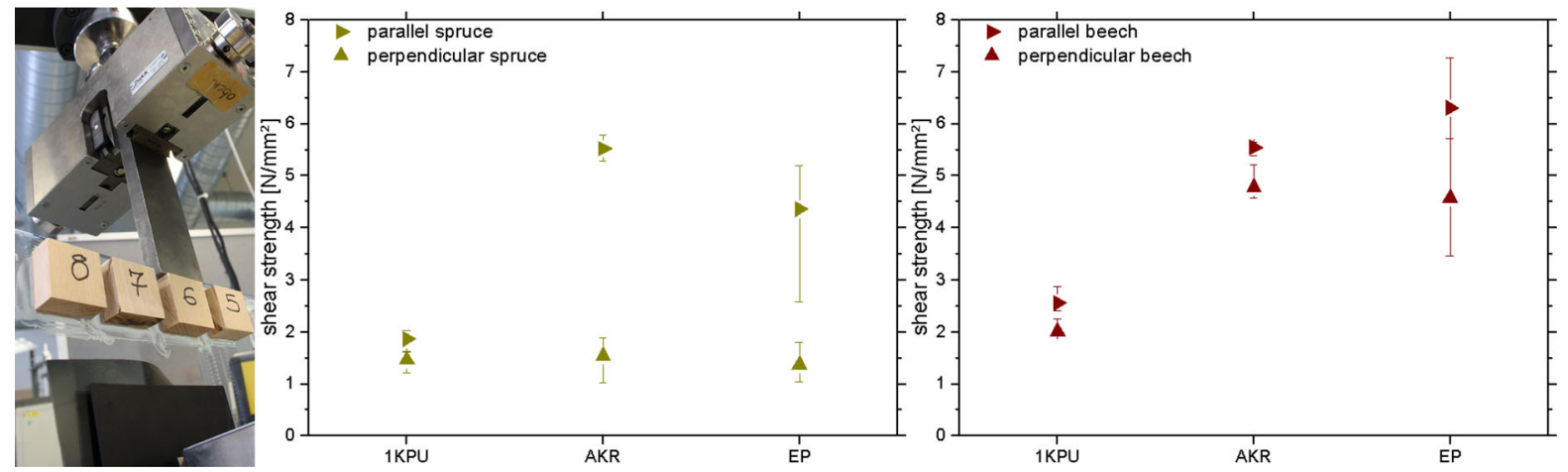

Fig. 8 Compressive shear strength, (left) principle of the test, (centre) spruce, (right) beech

labelled cycle, and lasts $24 \mathrm{~h}$. The cycle was selected to model an exaggeration of the weather in Bremen, the location of the bridge.

Specimens were removed after defined numbers of cycles, and tested in shear. The resulting development of lap shear strength over the number of cycles in depicted in Fig. 7 for each timber specie: for spruce, no significant decay of lap shear strength is observable, even after 10 cycles; on the contrary, for the acrylate, an increase is noticeable; regarding beech, the most prominent feature is the dramatic decay in strength for the epoxy after 4 cycles, which however is reversed for subsequent cycles; with oak, lap shear strength of epoxy decays from around 18-12 MPa within 10 cycles.

\subsection{Shear-compressive tests}

To complement the lap shear tests, additional investigations were performed on timber blocks $40 \times 40 \times$ $18 \mathrm{~mm}^{3}$ bonded on a glass plate, and subjected to compressive-shear, as documented in Fig. 8. In corresponding tests, with a procedure that did not follow a specific standard, load was applied parallel, and perpendicular to the timber grain. Without detailing all experimental results, summarized in Fig. 8, which basically confirms the lap shear tests for the case of testing parallel to the grain, it is important to notice that differences arise if timber is tested perpendicular to the grain: for the case of spruce, the differences are significant (up to 1:6 reduction for acrylate, 1:5 for the epoxy) unless adhesive failure is involved (as it is for the $1 \mathrm{C}$ polyurethane); for beech, which exhibits far better mechanical properties than spruce, the difference between the two loading directions are not as significant (reductions of a mere $10 \%$ for acrylate, below $20 \%$ for the epoxy).

\subsection{Additional tests on bonded timber-glass blocks}

Further tests were performed on relatively large sized timber blocks $\left(80 \times 80 \times 80 \mathrm{~mm}^{3}\right.$, cf. Fig. 9) of spruce on which glass plates of slightly larger size $\left(100 \times 100 \mathrm{~mm}^{2}\right)$ were bonded on both sides, and subsequently subjected to the same weathering cycles as 
Fig. 9 Additional weathering tests on bonded timber-glass blocks, (left) before testing, (right) after 22 cycles (top-left acrylate, top-right epoxy, bottom-left $1 \mathrm{C}$ polyurethane, bottom-right 2C polyurethane)
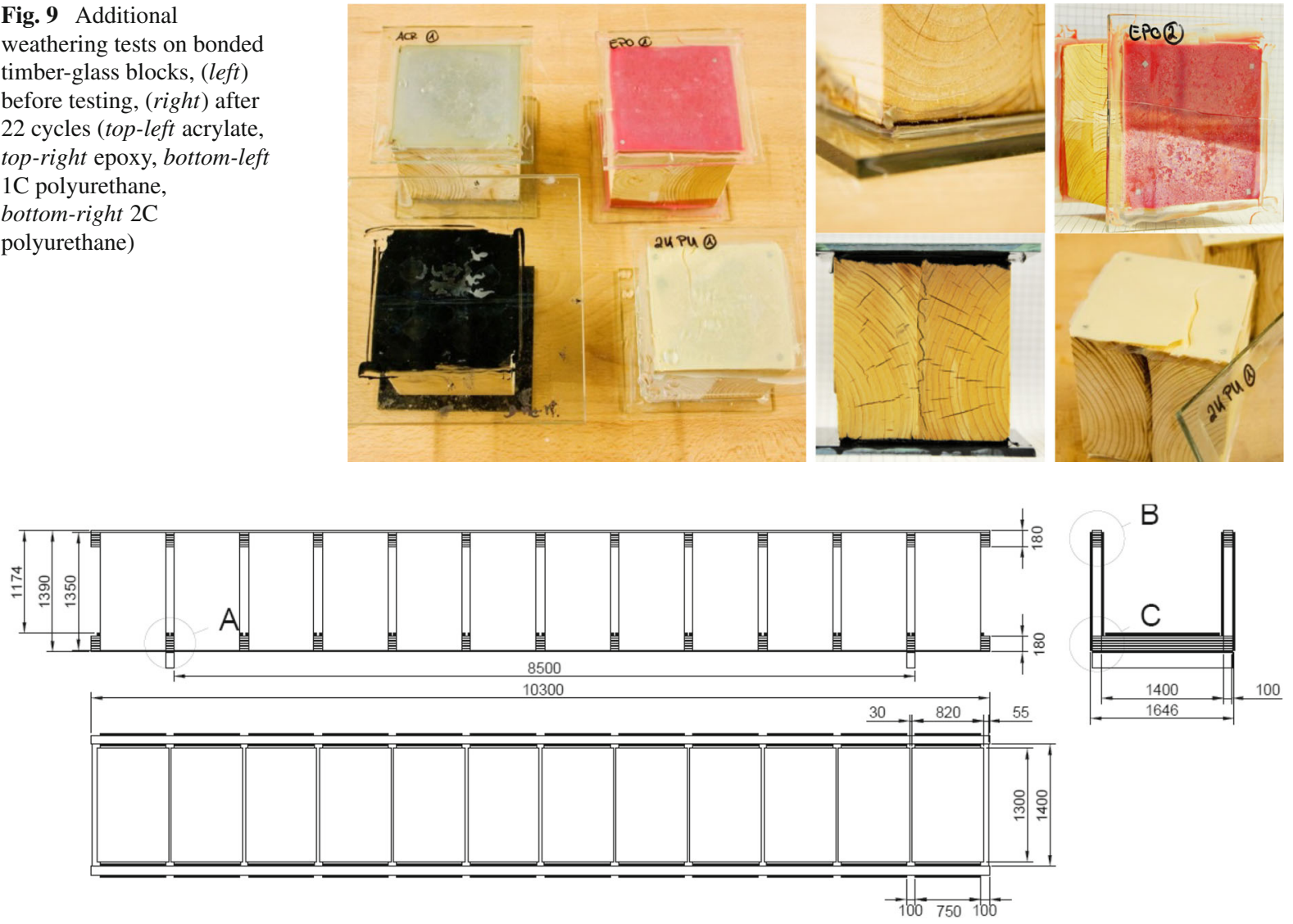

Fig. 10 Final design of the timber-glass pedestrian bridge with the main dimensions given (in $\mathrm{mm}$ )

for the lap shear tests, i.e. maintaining temperature for $12 \mathrm{~h}$ at $-20{ }^{\circ} \mathrm{C}$ and at a relative humidity level of $60 \%$, then raised to $+80{ }^{\circ} \mathrm{C}$ and $95 \%$ rel. humidity for another 12 hours. Four adhesives (acrylate, 2C epoxy, $1 \mathrm{C}$ polyurethane and $2 \mathrm{C}$ polyurethane) were tested this way to investigate their weathering stability; no mechanical testing was performed. Compared to the weathering effects observed for the lap shear tests, it was expected that this test setup would allow for more insights related to the swelling behaviour of the timber, respectively corresponding degradations.

The results showed the following: after a few cycles, the acrylate started debonding from the timber; a similar observation was made on the sample bonded with the $2 \mathrm{C}$-polyurethane, safe for the fact that debonding occurred at the glass interface; the 1C-polyurethane maintained good adhesion, but exhibited slight humidity filled meanders below the glass surface indicating that water had migrated inside the bonded connection.
The epoxy bonded specimen showed the most surprizing effect: after 22 cycles in the climatic chamber, it did not exhibit visible signs of damage; however, once removed from the device, and subjected to RT, the glass cracked.

\subsection{Summary of the investigations on the adhesives}

The experimental results on the load-bearing capacity of the different combinations of timber species and adhesives types yielded several conclusions, among them the following most important for the design:

- The traditional "soft" adhesives considered for bonding glass, herein 1C-PU, 2C-PU, and acrylate exhibit relatively low shear strengths, and usually fail at the timber interface

- In contrast to the aforementioned, the "stiffer" epoxies, as expected, allow for much higher mechanical performance 

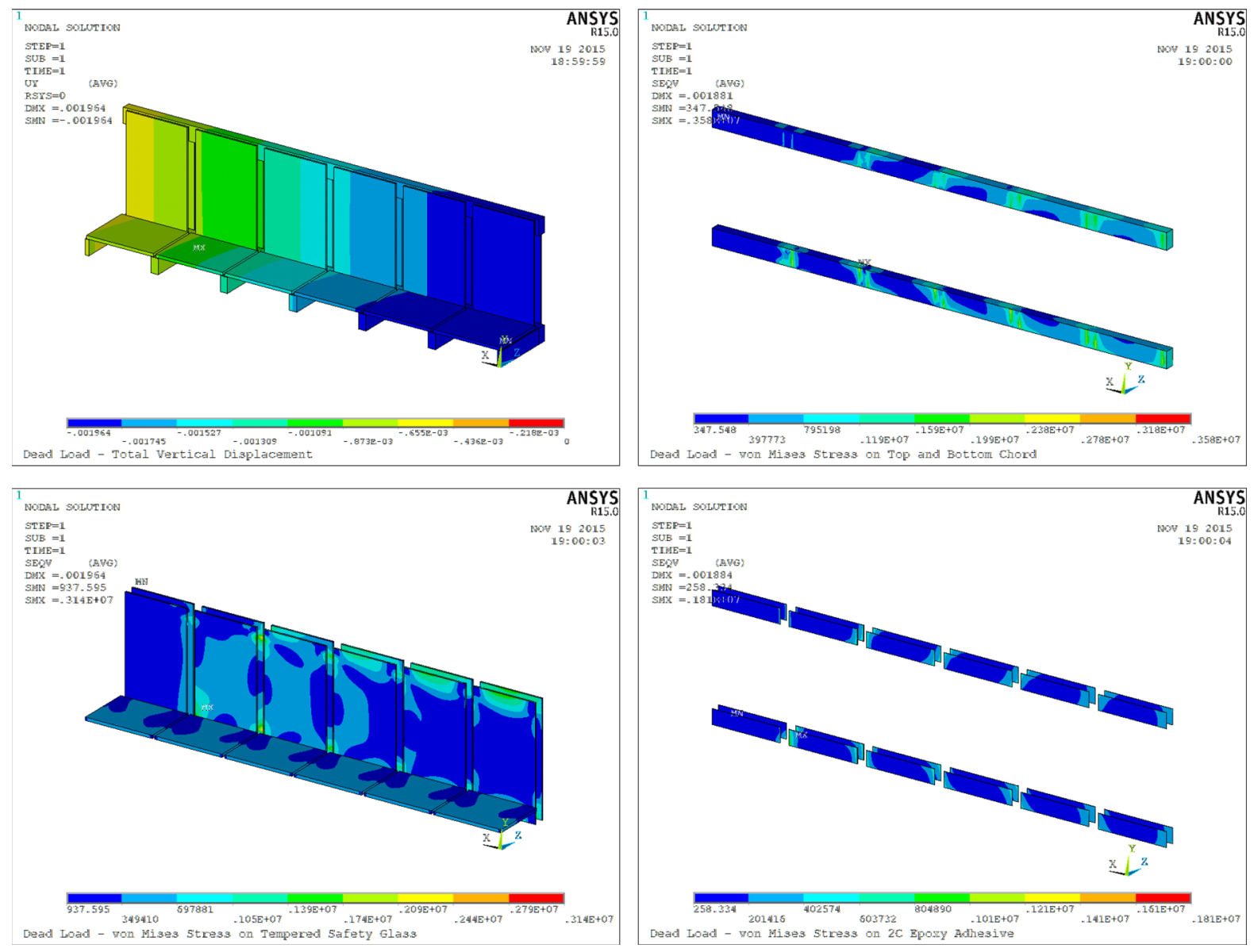

Fig. 11 Result of the numerical modelling for dead load: (top-left) vertical displacement; (top-right) stresses in the timber; (bottom-left) stresses in the glass panels; (bottom-right) stresses in the adhesive layer

- Glass was never the critical interface, except for the weathered 2C-PU; however, achieving adhesion on the different timber species was regarded critical, and only the two epoxies achieved this in all cases

- The effect of weathering on the strength of bonded timber-glass connections is strongly influenced by the timber species; with regard to this aspect, it is worth noting that beech is more critical than spruce or oak.

With regard to the mechanical performance of the timber, spruce was ruled out for its strong orthotropy, which resulted in a high disparity between the behaviour parallel and perpendicular to the fibre, as indicated in Fig. 8-(centre); this was considered critical because of the occurrence of shear stresses in both axes.

Based thereupon, it was decided to choose one of the two epoxies for the design. Although the silane's shear strength is consistently lower than that of the $2 \mathrm{C}$-epoxy, it seems much less prone to degradation with regard to weathering effects, as emphasised by the test data after several cycles. Additionally, the epoxysilane exhibits an E-modulus of $60 \mathrm{MPa}$, which is a magnitude below the corresponding value of the $2 \mathrm{C}$-epoxy (1700 MPa), which makes is potentially lest critical with regard to stresses induced by swelling. For the aforementioned reasons, the final design of the timber-glass bridge was done combining oak with the epoxysilane.

\section{Numerical modelling}

\subsection{Basis of the numerical modelling}

Based on the design principles stated before, and on the experimental investigations on the bonded timberglass interface, including taking into account effects 

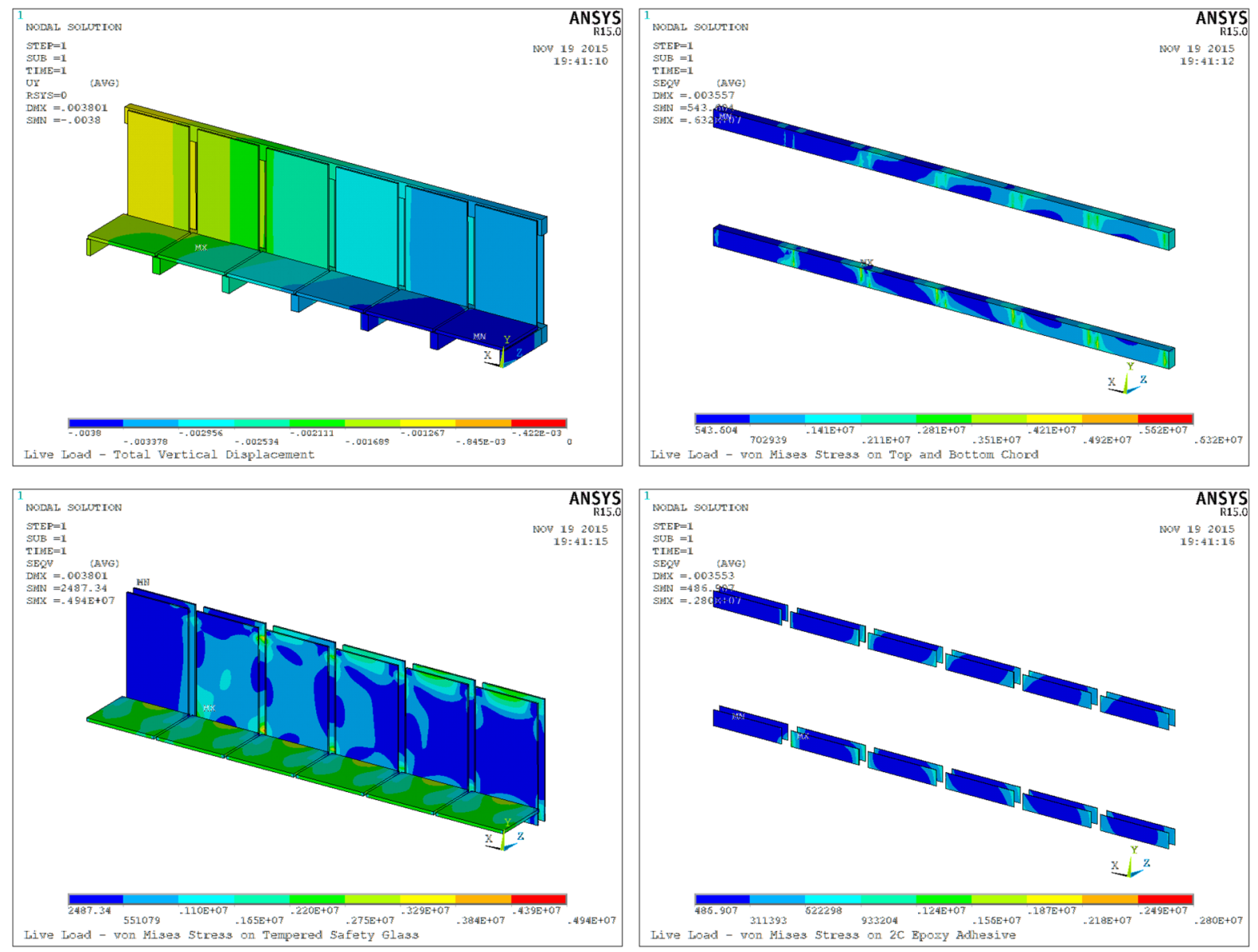

Fig. 12 Result of the numerical modelling for life load: (top-left) vertical displacement; (top-right) stresses in the timber; (bottom-left) stresses in the glass panels; (bottom-right) stresses in the adhesive layer

due to weathering, the design (depicted in Fig. 10) was finalised as follows:

- 4 Oak GLT-beams $180 \times 100 \mathrm{~mm}^{2}$ in section acting, in pairs, as upper and lower chord;

- 12 tempered security glass panels $1350 \times 750 \mathrm{~mm}^{2}$, with a thickness of $2 \times 10 \mathrm{~mm}$;

- As adhesive, Collano RS 8509 used to bond the glass panels to the timber beams, applied on both sides of the beams with a layer thickness of $3 \mathrm{~mm}$ so to compensate for material imperfections;

- 11 transverse oak-GLT-beams $180 \times 80 \mathrm{~mm}^{2}$ connected via glued-in rods (here the $2 \mathrm{C}$-epoxy can be used);

- 10 tempered security glass panels $1300 \times 750 \mathrm{~mm}^{2}$ with a thickness $3 \times 10 \mathrm{~mm}$ to act as running surface.
Material properties for the subsequent modelling were drawn from codes and standards (herein DIN EN 338, 14081-1, 1052), if not available were gathered from datasheets, or own testing. Numerical modelling was performed using commercial FE Software, herein Ansys in its version 15. A full 3D model was meshed with the higher-order three-dimensional 20node structural solid element SOLID186. The bridge was modelled as being supported on a neoprene bearing pads; one end simply supported, the other fixed such to achieve static determination. All bonded connections were assumed to be fully rigid; adhesives were modelled as linear materials using the initial stiffness, thus neglecting the potential benefit from load redistribution via yielding. Because of symmetry, only one quarter of the bridge was modelled, except for the results presented in 5.3. 

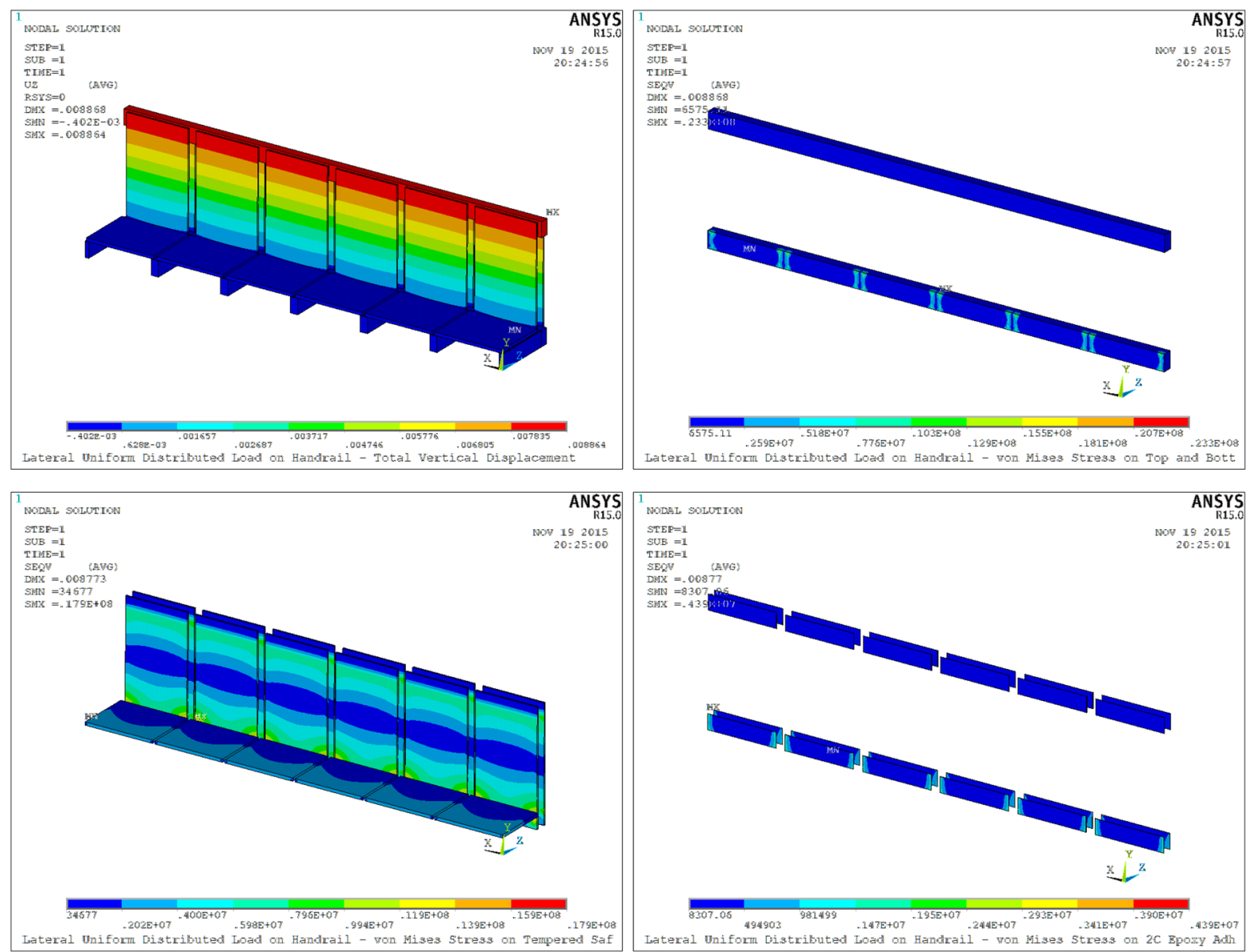

Fig. 13 Result of the numerical modelling for uniform line load on handrail: (top-left) vertical displacement; (top-right) stresses in the timber; (bottom-left) stresses in the glass panels; (bottom-right) stresses in the adhesive layer

Three load cases were considered:

- Firstly, dead weight which was modelled upon the material densities;

- Secondly, a live load of $5 \mathrm{kN} / \mathrm{m}^{2}$ acting on the running surface;

- Thirdly, a horizontal linear load of $1 \mathrm{kN} / \mathrm{m}$ acting on top of the upper chord which acts as a handrail.

Dead load was augmented with a load factor of $\mathrm{Y}=1.35$, all other loads were augmented by $\mathrm{Y}=1.5$ according to Eurocode. Loads were linearly superposed, without taking advantage of the possibility to reduce safety factors by load combinations.

\subsection{Numerical results}

Numerical results will be displayed as contour plots (Figs. 11, 12, 13), for each load case; summed up max-
Table 3 Maximum von Mises stresses, computed in MPa for each bridge component, except wood (for which Table 4 applies)

\begin{tabular}{lllll}
\hline \multirow{2}{*}{$\begin{array}{l}\text { Bridge } \\
\text { component }\end{array}$} & \multicolumn{3}{l}{ Maximum von Mises stresses (MPa) } & Total \\
\cline { 2 - 4 } & Dead load & Live load & Lateral & \\
\hline $\begin{array}{l}\text { Epoxysilane } \\
\text { Silicone }\end{array}$ & 1.81 & 2.80 & 0.44 & 5.05 \\
$\quad 0.06$ & 0.30 & 0.03 & 0.39 \\
$\begin{array}{l}\text { adhesive } \\
\text { Vertical }\end{array}$ & 3.14 & 4.94 & 1.79 & 9.87 \\
glass panels & & & & \\
$\begin{array}{l}\text { Glass slabs } \\
\text { Neoprene pad }\end{array}$ & 0.54 & 3.23 & 0.33 & 4.10 \\
\hline
\end{tabular}

imum stresses per bridge component will be gathered and presented separately in Table 3 .

For the sake of simplicity, and because stress levels were not critical for all bridge components other than 
Table 4 Maximum displacement vector sum, computed in $\mathrm{mm}$ for selected bridge component

\begin{tabular}{lllll}
\hline $\begin{array}{l}\text { Bridge } \\
\text { component }\end{array}$ & \multicolumn{2}{l}{$\begin{array}{l}\text { Maximum displacement } \\
\text { vector sum }(\mathrm{mm})\end{array}$} & Total \\
\cline { 2 - 4 } & Dead load & Live load & Lateral & \\
\hline $\begin{array}{l}\text { Longitudinal } \\
\text { wood }\end{array}$ & 1.88 & 3.56 & 0.89 & 6.33 \\
$\begin{array}{l}\text { Transverse } \\
\text { wood }\end{array}$ & 1.96 & 3.73 & 0.09 & 5.78 \\
$\begin{array}{l}\text { Vertical } \\
\text { glass panels }\end{array}$ & 1.88 & 3.58 & 0.88 & 6.34 \\
\begin{tabular}{l} 
Glass slabs \\
\hline
\end{tabular} & 1.96 & 3.80 & 0.08 & 5.84 \\
\hline
\end{tabular}

wood, van Mises stresses are reported in Table 3; the case of wood being addressed subsequently.

Regarding wood, in particular the longitudinal beams, two verifications were made, and each using two different sets of material resistance parameters:

1. A maximum stress based criterion, with mechanical resistance drawn from DIN 1052, resp. using orthotropic characteristic values (5\%-quantile). If using mechanical resistance originating from DIN1052, the maximum stress criterion reaches a value of $6.08+7.43=\mathbf{1 3 . 5 1}>\mathbf{1}$, indicating failure. However, it drops to an acceptable values of $0.54+0.45=\mathbf{0 . 9 9}<\mathbf{1}$ considering characteristic values from own experimental data, which includes the reduction factors for the different load durations (cf. Sect. 3.2)

2. A Tsai-Wu criterion, which comes close to the widely accepted Norris (1962) criterion, with mechanical resistance drawn from DIN 1052, resp. using orthotropic characteristic values (5\%quantile); similarly, considering timber strength data from DIN 1052 would lead to a value of $\mathbf{4 0 . 7 4}>\mathbf{1}$, while using realistic own experimental data leads to a mere $0.94<\mathbf{1}$.

In both cases corresponding Fig. 14 depict the values of the criteria. It appears that in all cases maximum values correspond to well delimited stress peaks are limited to areas close to the supports, and the corners of the contact area between timber, adhesive and glass. In all cases they represent stress concentrations.

Since these stress peaks concentrate on small areas of the structure, their magnitude could be relieved considering the plastic behaviour of the adhesive (not considered in the current FEA). Independently of the aforementioned, the authors considered it legitimate to amend current codes with own validated experimental data, in particular if it has been considered at the $5 \%$-quantile level.

\subsection{Modelling the redundancy}

Additional modelling was performed to test the redundancy of the bridge with regard to failure of selected glass panels; to not overload this publication, results, displayed in Fig. 15, will only be summarized.

Numerical calculations were performed at the same system, but sequentially removing selected glass panels; the result was that removing one panel almost doesn't affect the stress distribution in the structure with increases below $1 \%$, removing two panels leads to an increase in the range of some 5-6\% in both stresses and deformations, only if two adjacent panels are destroyed does stress redistributions lead to local increases of $8-10 \%$.

However, codes allow reducing all partial safety factors to 1.0 in particular emergency situations, e.g. in fire; it is reasonable to consider the rupture of a tempered safety glass panel as such a situation, which in turn more than compensates for the partial loss of structural integrity.

\subsection{Summary of numerical modelling}

- Structural verification of the timber was performed considering a maximum stress criterion, and a TsaiWu criterion;

- If considering mechanical resistances originating from codes (DIN 1052), verification fails at limited hot spots of the structure (bearings, and the edges of the bonded glass panels);

- If considering experimental strength data at the $5 \%$-quantile level, i.e. characteristic values, verification is achieved, since both criteria (maximum stress, Tsai-Wu) remain below 1, even if considering long term loads (dead load).

- Regarding the adhesive, the maximum stress cumulated from all load cases is equal to 5.05 MPa, which ranges below the lap shear strength after weathering; the authors considered this to be sufficient safe.

- The tempered safety glasses are, under the combination of all considered loads, stressed to a value of 


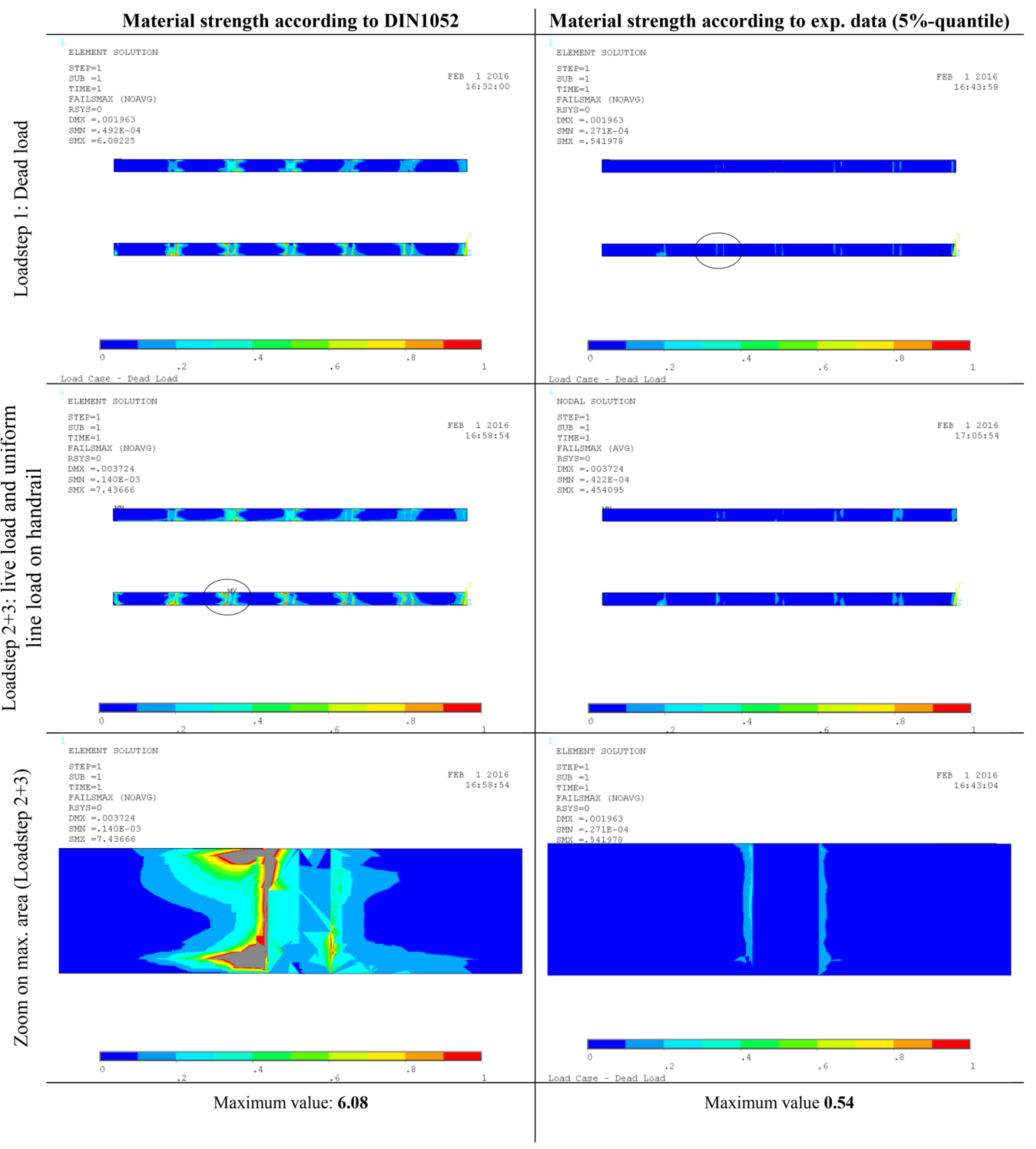

Fig. 14 Failure criteria applied to the longitudinal beams

up to $9.87 \mathrm{MPa}$ (lateral panels); a value far beyond the capacity of common tempered safety glasses;

- Maximal deflection of the bridge, as calculated, amounts to a mere $6.33 \mathrm{~mm}$, which represents a value below 1/1000 of span, leaving sufficient safety margin for creep deformations not considered herein;

- The structural integrity of the hybrid structures remains intact, even if some of the glass panels are destroyed, which indicates that a certain form of 

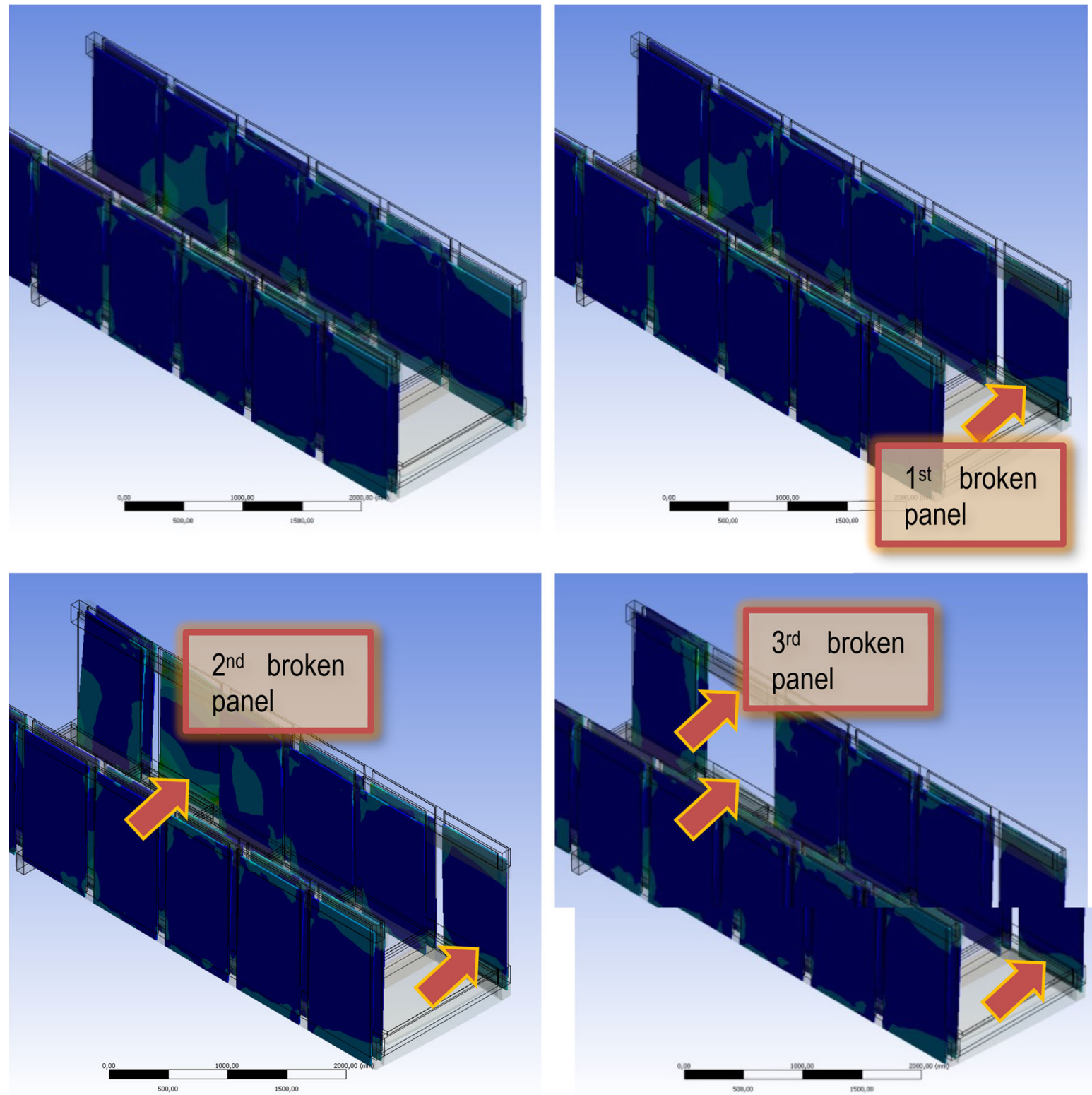

Fig. 15 Effect of subsequently damaging glass panels (arrows indicate missing panels)

redundancy can be obtained, despite the very brittle nature of the bridge components.

\section{Conclusions}

Adhesively bonded hybrid structures involving glass as load bearing elements remain challenging to design. The latter is particular true when glass is combined with a relatively material exhibiting relative complexity, as is it the case with timber.

The design process described in this publication presents some of the principles behind adhesiveadapted design, experimental work necessary to select the right combination of materials as well as a methodology for structural verification, including a proposal to achieve a certain level of redundancy. However, it also shows that current timber codes severely underestimate 
strength for stress components that are critical in the context of bonding; it is though legitimate and possible to amend corresponding standards using experimental data.

Based thereupon, it is planned to build the bridge in the upcoming months, giving an opportunity to physically test the validity of the concept.

\section{Compliance with ethical standards}

Conflict of interest On behalf of all authors, the corresponding author states that there is no conflict of interest.

\section{References}

Blyberg, L., Lang, M., Lundstedt, K., Schander, M., Serrano, E., Silfverhielm, M., Stålhandske, C.: Constr. Build. Mater. 55, 470-478 (2014)

Blyberg, L., Serrano, E., Enquist, B.: Sterley. Int. J. Adhes. Adhes. 35, 76-87 (2012)

Blyberg, L., Serrano, E., Enquist, B.: Sterley. Int. J. Adhes. Adhes. 35, 76-87 (2012)

Cruz, P., Pequeno, J.: On Architectural and Structural Applications of Glass. Delft, The Netherlands (2008)

Edl, T.: Doctoral thesis. University of Technology, Vienna (2008)

ETAG 002: Teil 1: Gestützte und ungestützte Systeme-Leitlinie für die Europäische technische Zulassung für geklebte Glaskonstruktionen (1998)

Fadai, A., Winter, W.: In proceedings Challenging Glass 4 \& COST Action TU0905 Final Conference. CRC Press (2014)

Fecht, S., Vallée, T., Tannert, T., Fricke, H.: Adhesively bonded hardwood joints under room- and elevated temperatures. J. Adhes. (2013). doi:10.1080/00218464.2013.836968
Hochhauser, W., Winter, W.: Fadai A Glasbau 82(S1), 185-200 (2013)

Hochhauser, W.: Ein Beitrag zur Berechnung and Bemessung von geklebten und geklotzten Holz-Glas-Verbundscheiben. PhD-Thesis, TU Wien (2011)

Jiang, Y., Schaffrath, J., Knorz, M., Winter, S.: In proceedings RILEM Conference Materials and Joints in Timber Structures-Recent Advancement of Technology, Stuttgart, Germany (2014)

Keller, T.: Towards structural forms for composite fibre materials. Struct. Eng. Int. 9(4), 297-300 (1999)

Kozłowski, M.: Hybrid glass beams. Review of research projects and applications. Arch. Civ. Eng. Environ. 5, 53-62 (2012)

Kreher, K., Natterer, J., Natterer, J.: Timber-glass-composite girders for a hotel, Switzerland. Struct. Eng. Int 2, 149-151 (2004)

Mainstone, R.J.: Structural analysis, structural insights, and historical interpretation. J. Soc. Arch. Hist. 56, 316-340 (1997)

Müller, C.: Experimentelle und theoretische Untersuchungen zu Holz-Glas-Verbundträgern", Master Thesis, University of Vienna/Austria (2011)

Neubauer, G.: Entwicklung and Bemessung von statisch wirksamen Holz-Glas-Verbundkonstruktionen zum Einsatz im Fassadenbereich. PhD-Thesis, TU Wien (2011)

Norris, C.B.: Strength of orthotropic materials subjected to combined stresses (1962)

Pequeno, J., Cruz, P.: Structural timber-glass linear system: characterization \& architectural potentialities. Glass performance days, Tampeere, Finland (2009)

Peters, T.F.: Building the Nineteenth Century. MIT Press, Cambridge (1996)

Rinnhofer, M.: Dissertation Technical University Vienna (2014) 